\title{
A New Method of Mueller-Matrix Diagnostics and Differentiation of Early Oncological Changes of the Skin Derma
}

\author{
Yu. A. Ushenko, ${ }^{1}$ A. P. Peresunko, ${ }^{2}$ and Bozan Adel Baku ${ }^{2}$ \\ ${ }^{1}$ Correlation Optics Department, Chernivtsi National University, 2 Kotsyubinsky Str., 58012 Chernivtsi, Ukraine \\ ${ }^{2}$ Chernivtsi State Medical University, 2 Theatral Sq, 58002 Chernivtsi, Ukraine
}

Correspondence should be addressed to Yu. A. Ushenko, o.ushenko@chnu.edu.ua

Received 3 December 2009; Revised 18 March 2010; Accepted 29 March 2010

Academic Editor: Oleg V. Angelsky

Copyright ( $) 2010 \mathrm{Yu}$. A. Ushenko et al. This is an open access article distributed under the Creative Commons Attribution License, which permits unrestricted use, distribution, and reproduction in any medium, provided the original work is properly cited.

\begin{abstract}
The paper deals with investigation of the processes of laser radiation transformation by biological crystals networks using the singular optics techniques. The results obtained showed a distinct correlation between the points of "characteristic" values of coordinate distributions of Mueller matrix $\left(M_{\mathrm{ik}}=0, \pm 1\right)$ elements and polarization singularities (L- and C-points) of laser transformation of biological crystals networks with the following possibility of Mueller-matrix selection of polarization singularity. The technique of Mueller-matrix diagnostics of pathological changes of skin derma is proposed.
\end{abstract}

\section{Introduction}

Laser polarimetry [1] enabling to obtain information about optical anisotropy [2-5] of biological tissues (BT) is an important direction of noninvasive diagnostics of organic phase-heterogeneous layers. For statistic analysis of such polarimetric information a model approach has been worked out based on the following conditions $[1,2,6-12]$ :

(i) all the variety of human BT can be represented by four main types-connective, muscular epithelial, and neural tissues; (ii) structure of any BT type is regarded as a twocomponent amorphous-crystalline one;

(iii) the crystalline component or extracellular matrix is formed by the network of optically uniaxial birefringent protein (collagen, myosin, elastine, etc.) fibrils or biological crystals;

(iv) the process of transformation of laser radiation polarization state by biological crystal is characterized by Mueller $\{M\}$ matrix operators of an optically uniaxial crystal

$$
\{M\}=\left\|\begin{array}{cccc}
1 & 0 & 0 & 0 \\
0 & M_{22} & M_{23} & M_{24} \\
0 & M_{32} & M_{33} & M_{34} \\
0 & M_{42} & M_{43} & M_{44}
\end{array}\right\|=\left\|\begin{array}{cccc}
1 & 0 & 0 & 0 \\
0 & \left(\cos ^{2} 2 \rho+\sin ^{2} 2 \rho \cos \delta\right) & \cos 2 \rho \sin 2 \rho(1-\cos \delta) & (\sin 2 \rho \sin \delta) \\
0 & (\cos 2 \rho \sin 2 \rho(1-\cos \delta)) & \left(\sin ^{2} 2 \rho+\cos ^{2} 2 \rho \cos \delta\right) & (\cos 2 \rho \sin \delta) \\
0 & (-\sin 2 \rho \sin \delta) & (-\cos 2 \rho \sin \delta) & (\cos \delta)
\end{array}\right\| .
$$

Here $\rho$-direction of optical axis of biological crystal with birefringence index $\Delta n, \delta=(2 \pi / \lambda) \Delta n l$-phase shift between orthogonal components of the amplitude of a probing laser beam with wave length $\lambda$. 


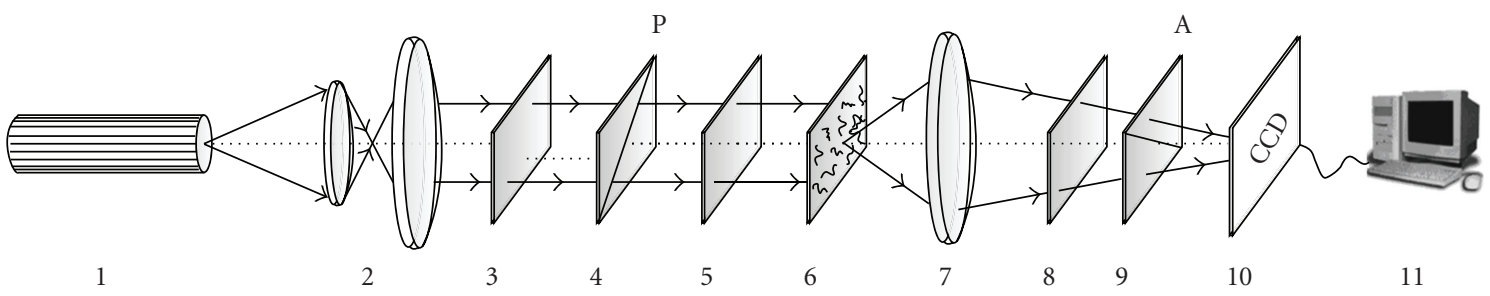

Figure 1: Optical scheme of polarimeter, where 1: He-Ne laser; 2: collimator; 3: stationary quarter-wave plates; 5 , 8: mechanically movable quarter-wave plates; 4, 9: polarizer and analyzer correspondingly; 6: object of investigation; 7: microobjective; 10: CCD camera; 11: personal computer.

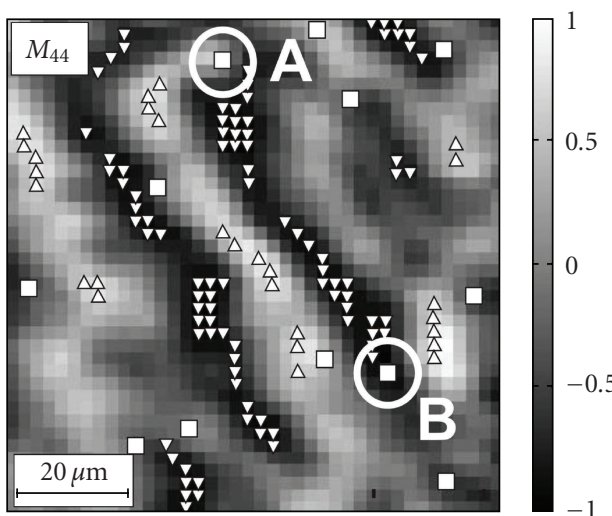

(a)

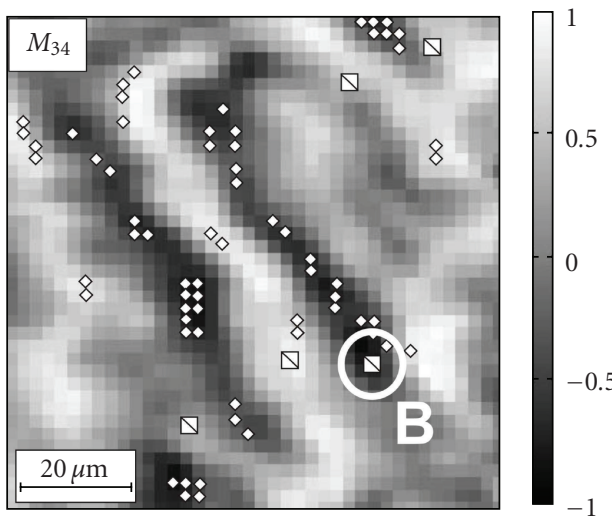

(c)

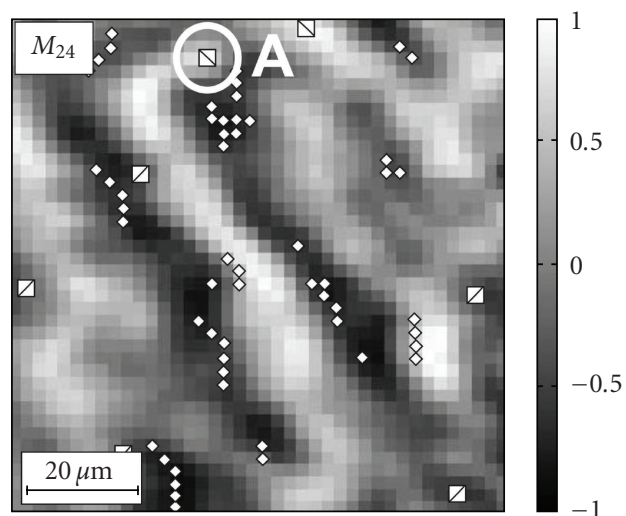

(b)

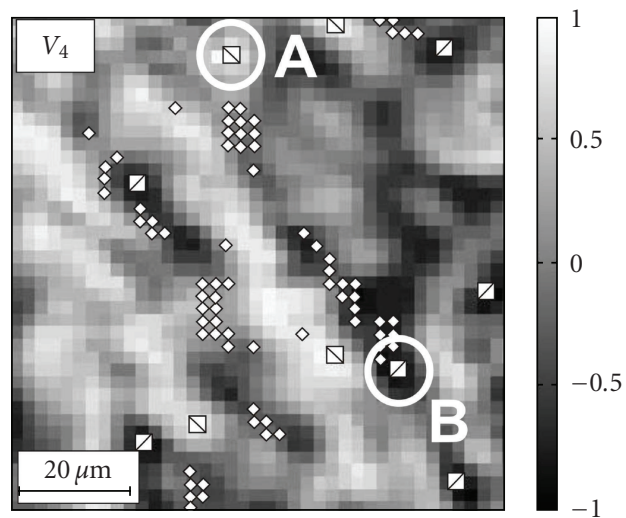

(d)

Figure 2: Networks of characteristic values $M_{44,24,34}^{*}(m \times n)$ of matrix elements $M_{44,24,34}(\mathrm{a}, \mathrm{b}, \mathrm{c})$ and singularities of polarization image of the skin derma layer histological section $V_{4}$ (“d”): “ \pm C"-points $(\square)\left(M_{44}=0\right)$; “+C"-points $(\nabla)\left(M_{24,34}=+1, V_{4}=+1\right)$; “-C"-points $(\square)$ $\left(M_{24,34}=-1, V_{4}=-1\right)$; “+L”-points $(\Delta)\left(M_{44}=+1\right)$; “-L”-points $(\nabla)\left(M_{44}=-1\right)$; “ \pm L”-points $(\diamond)\left(M_{24,34}=0, V_{4}=0\right)$.

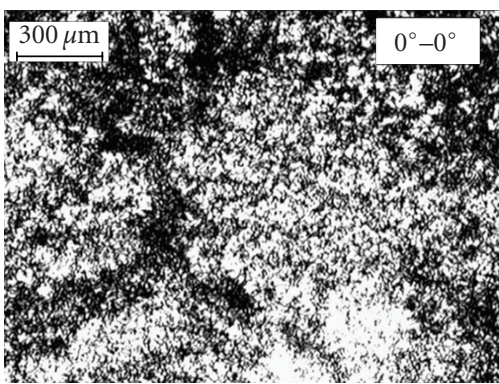

(a)

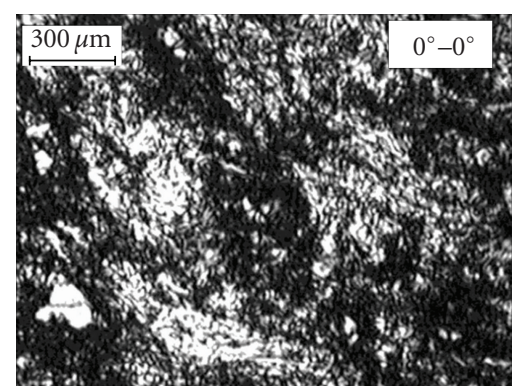

(b)

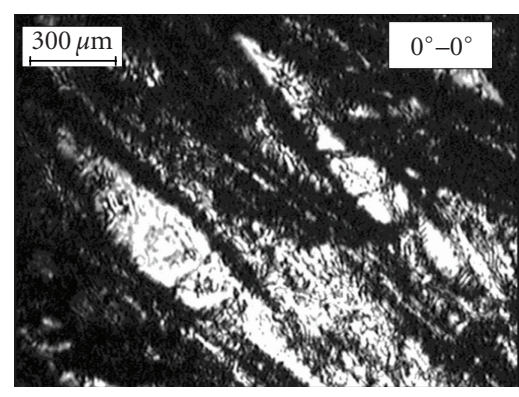

(c)

Figure 3: Polarization images of the skin derma “A” (a), “B” (b), and “ $\mathrm{C}$ ” (c)-types in coaxial polarizer and analyzer. 
A new approach to description of the BT laser images based on the analysis of coordinate distributions of polarization singularities became developed the above-mentioned statistical [13-22]. Linearly (L-points) and circularly (Cpoints) polarized states of light oscillations belong to them. For L-points the direction of the electric-intensity vector's rotation is indefinite (singular). For a C-point, the polarization azimuth of the electric intensity vector is indefinite.

Investigation of laser images of the connective tissue layers revealed a developed network of polarization singularities [23-26], which was quantitatively estimated in the form of distribution of the amount of L- and C-points. By means of the analysis of the given distribution's statistical moments of the 1st-4th orders (the technique of polarization mapping) the criteria of diagnostics of oncological changes of uterus neck tissue were found.

It should be pointed out that singular approach is predominantly realized out of the analysis of the mechanisms of forming polarizationally heterogeneous laser images of BT by an extracellular matrix. Thus, development of laser polarimetry techniques based on determination of singular interconnections "object-field" in order to find new methods of diagnostics of transformation of the BT extracellular matrix orientation-phase structure connected with precancer changes of their physiological state is very important.

To solve such a problem, we should revert to the analysis of optical properties of biological crystals' nets, comprehensively described by the Mueller matrix though within a singular approach.

\section{A Brief Theory of the Mueller Matrixes Approach in the Analysis of the Biological Tissue Birefringent Nets Polarization Properties}

The use of the fourth parameter of the Stokes vector appears to be a suitable and widely applied means of such singularities representation

$$
V_{4}=\left\{\begin{array}{l}
0 \longleftrightarrow L \\
\pm 1 \longleftrightarrow C .
\end{array}\right.
$$

According to analysis of (1) and (2), one can see the interconnection between the polarization singular states and certain (characteristic) values of orientation $\rho^{*}$ and phase $\delta^{*}$ parameters of the BT crystals' nets of the extracellular matrix

$$
\begin{aligned}
& \rho^{*}=0^{0} ; \pm 45^{0} 90^{0} ; \\
& \delta^{*}=0^{\circ}, 90^{\circ}, 180^{\circ} .
\end{aligned}
$$

As it can be seen, relations (3) are the necessary terms for forming polarization singular states of the laser beam (L$\left(\delta=0^{\circ}, 180^{\circ}\right)$ and C- $\left(\delta= \pm 90^{\circ}\right)$ points $)$ by optically coaxial birefringent crystal.
Considering expressions (1)-(3) the characteristic values $M_{\mathrm{ik}}^{*}$ were defined that determine the L- and C-points in laser image of the extracellular matrix of the BT layer:

(i) the values $M_{44}=0$ and $V_{4}= \pm 1$ determine the complete set of \pm C-points $\left(\delta= \pm 90^{\circ}\right)$;

(ii) the complete set of L-points $\left(\delta=0^{\circ}\right)$ of the laser image is caused by the terms $M_{22}=M_{33}=M_{44}=1$ and $V_{4}=0$.

Mueller-matrix analysis enables to perform the sampling of polarization singularities of the laser image, formed by biological crystals with orthogonally oriented $\left(\delta=0^{\circ}, 90^{\circ}\right.$ and $\delta=45^{\circ}, 135^{\circ}$ ) optical axes to

(i) "orthogonal" \pm C-points

$$
\begin{gathered}
M_{33}=0, M_{34,43}= \pm 1- \pm \mathrm{C}-\left(\rho=0^{\circ}, 90^{\circ}\right), \\
M_{22}=0, M_{24,42}= \pm 1- \pm \mathrm{C}-\left(\rho=45^{\circ}, 135^{\circ}\right) .
\end{gathered}
$$

(ii) “orthogonal” $\mathrm{L}_{0 ; 90}$ - and $L_{45 ; 135}$ - points

$$
\begin{gathered}
M_{24,42}=0-\mathrm{L}_{0^{\circ}, 90^{\circ}}-\left(\rho=0^{\circ}, 90^{\circ}\right), \\
M_{34,43}=0-\mathrm{L}_{45^{\circ}, 135^{\circ}}\left(\rho=45^{\circ}, 135^{\circ}\right) .
\end{gathered}
$$

Thus, measuring the coordinate distributions of the characteristic values $\left(M_{\mathrm{ik}}^{*}=0, \pm 1\right)$ of the BT Mueller matrix elements enables not only to foresee the scenario $\left(M_{\mathrm{ik}}^{*} \rightarrow\right.$ $V_{4}^{*}$ ) of forming the ensemble of polarization singularities $\left(V_{4}=0, \pm 1\right)$ of its image, but also to additionally realize their differentiation, conditioned by the specificity of orientation structure of biological crystals.

\section{The Scheme and Methods of Experimental Investigations}

Figure 1 shows traditional optical scheme of polarimeter for measuring due to Gerrard technique [27] of Stokes parameters and elements of Mueller matrix of the BT histological sections.

The parallel $\left(\varnothing=10^{4} \mu \mathrm{m}\right)$ beam of He-Ne laser $(\lambda=$ $0.6328 \mu \mathrm{m}, W=5.0 \mu \mathrm{W})$ was used as an illuminator. Polarization illuminator consists of quarter-wave plates 3, 5 and polarizer 4 , and it sequentially forms a series of linearly polarized $\left(I_{0}, I_{45}, I_{90}, I_{135}\right)$ with azimuths $0^{\circ}, 90^{\circ}$, $45^{\circ}, 135^{\circ}$, and right-hand $\left(I_{\otimes}\right)$ and left-hand $\left(I_{\oplus}\right)$ circularly polarized probing BT laser beams. The BT images made by microobjective $(4 \times) 7$ were projected into the plane of a light-sensitive plate $(m \times n=800 \times 600$ pixels $)$ of CCD-camera 10. Polarization analysis of the BT images was performed by means of polarizer 9 and quarter-wave plate 8 .

The optical thin (the absorption coefficient $\tau<0,1$ ) BT histological sections were used as the objects of investigation. In this situation, one has a single scattering regime of laser radiation scattered by BT network and the narrowband scattering indicatrix is formed (95\% of energy is 


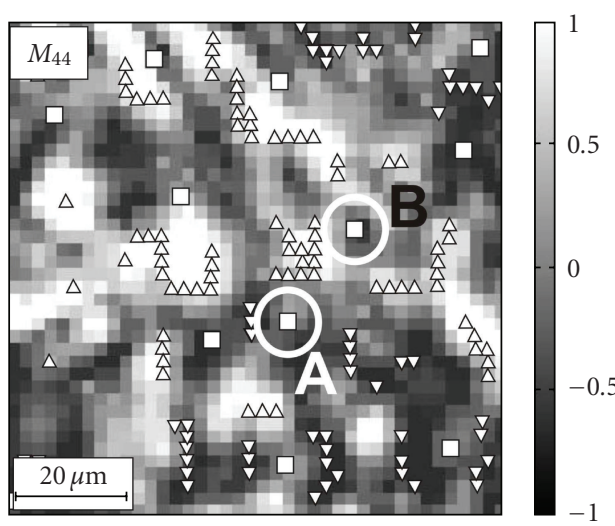

(a)

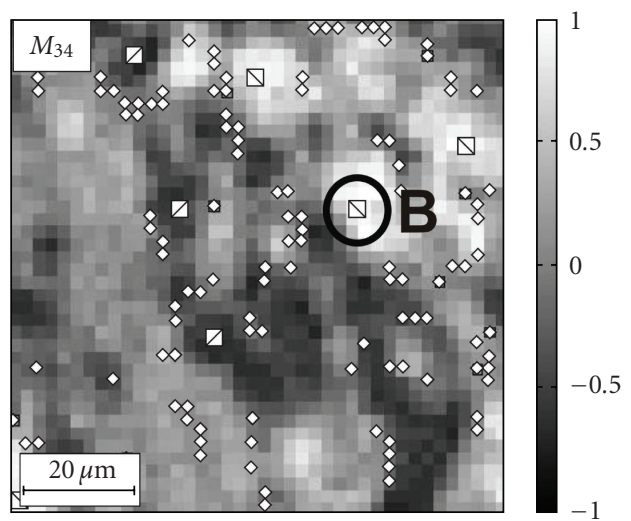

(c)

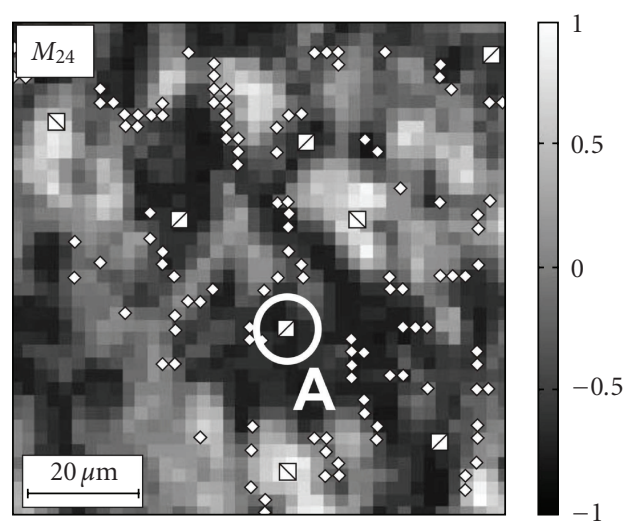

(b)

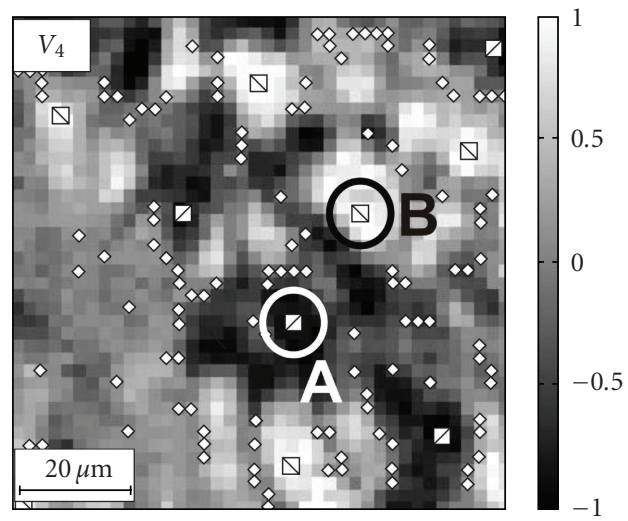

(d)

FIGURE 4: Networks of characteristic values $M_{44,24,34}^{*}(m \times n)$ of matrix elements $M_{44,24,34}(\mathrm{a}, \mathrm{b}, \mathrm{c})$ and singularities of polarization image of skin derma histological section of “A”-type $V_{4}(\mathrm{~d})$ : “ \pm C"-points $(\square)\left(M_{44}=0\right)$; “+C"-points $(\nabla)\left(M_{24,34}=+1, V_{4}=+1\right)$; “-C"-points $(\square)$ $\left(M_{24,34}=-1, V_{4}=-1\right)$; “+L”-points $(\Delta)\left(M_{44}=+1\right)$; “-L”-points $(\nabla)\left(M_{44}=-1\right)$; “ \pm L”-points $(\diamond)\left(M_{24,34}=0, V_{4}=0\right)$.

concentrated within the angle cone $\left.\Delta \Omega \leq 15^{0}\right)$. Therefore, the speckle background formation in the BT histological section image due to scattering on optical elements is insignificant.

At the first stage the interconnections $\left(M_{\mathrm{ik}}^{*} \rightarrow V_{4}^{*}\right)$ of matrix and polarization singularities were investigated on the example of histological section of healthy skin derma layer.

Figure 2 represents coordinate distributions of matrix elements $M_{44,24,34}(m \times n)$ of histological section of skin derma and the fourth parameter $V_{4}(m \times n)$ of its image's Stokes vector with the characteristic values $0, \pm 1$ plotted on them (within the marked 100 pix $\times 100$ pix sampling plot).

It can be seen from the data obtained that there is direct correlation between the coordinate $(k, g 1 \leq k \leq m, 1 \leq g \leq$ $n)$ positions of characteristic values of the matrix element $M_{44}^{*}$ of skin derma and the network of L- and C-points of its laser image $\left\{M_{44}^{*}(k, g)=\left\{\begin{array}{c}0 \\ \pm 1\end{array}\right\} \Leftrightarrow V_{4}^{*}(k, g)=\left\{\begin{array}{c} \pm 1- \pm C \\ 0-L\end{array}\right\}\right\}$ (Figures 2(a) and 2(d)).

Coordinate distributions of characteristic values of matrix elements $M_{24,42}^{*}(m, n), M_{34,43}^{*}(m, n)$ and corresponding networks of "orthogonal" $\mathrm{L}_{0,90^{-}}, \mathrm{L}_{45,135^{-}}$and $\mathrm{C}_{0,90^{-}}$, $\mathrm{C}_{45,135}$-points (relations (4) and (5)) possess individual structure. Such peculiarities of singular networks of laser image of skin derma are obviously conditioned by the asymmetry of various directions $\left(\rho=0^{\circ}, 90^{\circ}\right.$ and $\rho=45^{\circ}$, $135^{\circ}$ ) of orientation of optical axes of biological crystals in the plane of the investigated sample (Figures 2(b) and 2(c)).

Analytically substantiated and experimentally proven interconnections between the matrix and polarization singularities were used as the basis for Mueller-matrix singular diagnostics of oncological changes of the tissues of women's reproductive sphere.

\section{Mueller-Matrix Diagnostics and Differentiation of Pathological Changes of the Skin Derma}

Three groups of histological sections of the main tissue of skin derma-were used as the objects of investigation:

(i) biopsy of the sound tissue of skin derma (type "A"Figure 3(a));

(ii) biopsy of the skin derma in precancer state (type "B"-Figure 3(b)); 


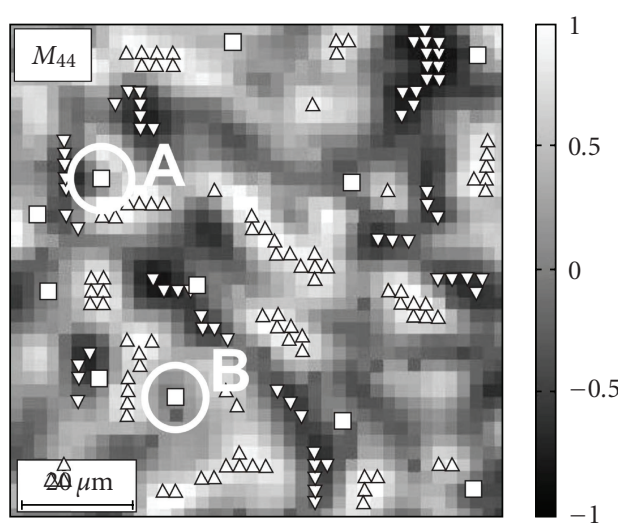

(a)

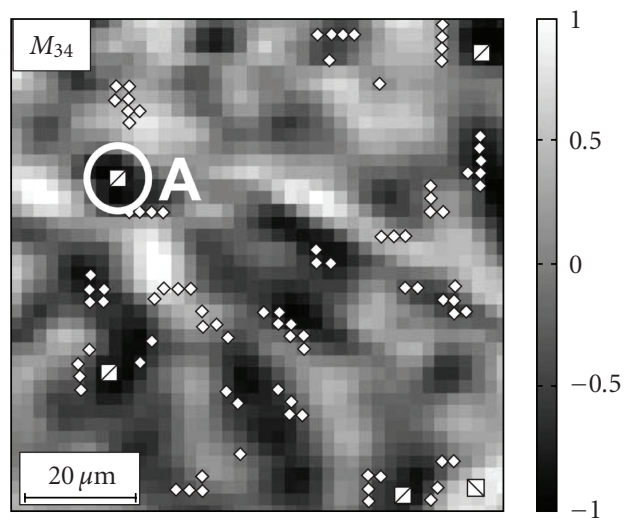

(c)

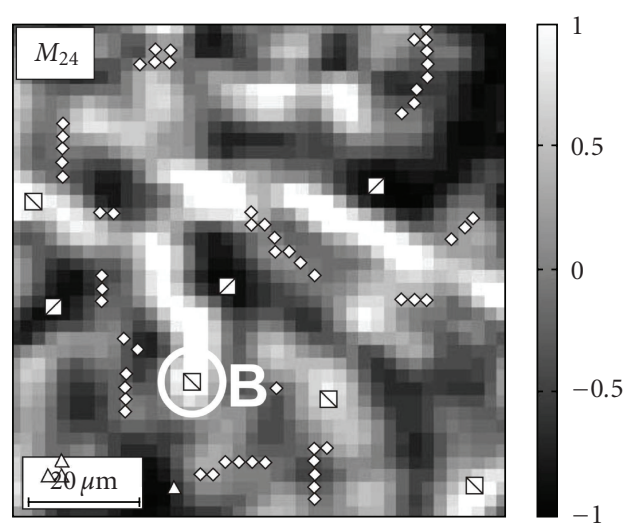

(b)

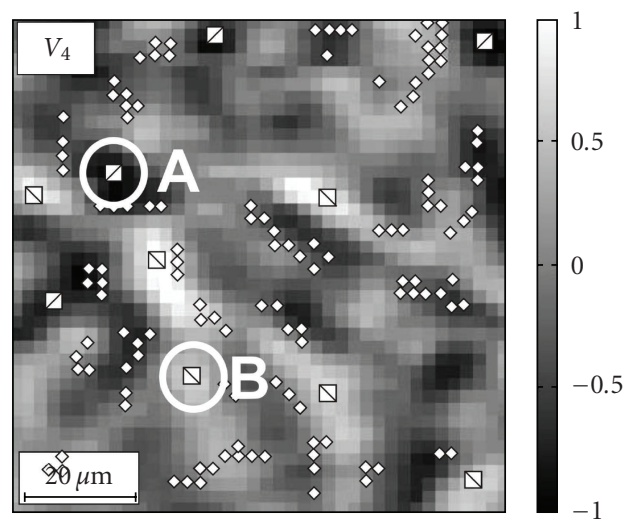

(d)

FIGURE 5: Networks of characteristic values $M_{44,24,34}^{*}(m \times n)$ of matrix elements $M_{44,24,34}(\mathrm{a}, \mathrm{b}, \mathrm{c})$ and singularities of polarization image of skin derma histological section of “B”-type $V_{4}(\mathrm{~d})$ : “ \pm C"-points $(\square)\left(M_{44}=0\right)$; “+C"-points $(\nabla)\left(M_{24,34}=+1, V_{4}=+1\right)$; “-C”-points $(\square)$ $\left(M_{24,34}=-1, V_{4}=-1\right)$; “+L"-points $(\Delta)\left(M_{44}=+1\right)$; “-L”-points $(\nabla)\left(M_{44}=-1\right)$; “ \pm L”-points $(\diamond)\left(M_{24,34}=0, V_{4}=0\right)$.

(iii) biopsy of the skin derma in cancer state (type " $\mathrm{C}$ "Figure 3(c)).

To determine the criteria of Mueller-matrix diagnostics of skin derma oncological state and differentiation of its severity degree the following technique was used:

(i) coordinate networks of characteristic values of matrix elements $M_{44,24,34}^{*}(m \times n)=0, \pm 1$ were scanned in the direction $x \equiv 1, \ldots, m$ with the step $\Delta x=1$ pixel;

(ii) within the obtained sampling $\left(1_{\text {pix }} \times n_{\text {pix }}\right)^{(k=1,2, \ldots, m)}$ for coordinate distribution of the element $M_{44}(m \times n)$ the total amount $\left(N^{(k)}\right)$ of characteristic points $(0$, \pm 1 ), which set the complete ensemble of singular points was calculated and the dependencies $N(x) \equiv$ $\left(N^{(1)}, N^{(2)}, \ldots, N^{(m)}\right)$ were determined;

(iii) distributions of the number of "orthogonal" singular $\mathrm{L}$ - and $\pm \mathrm{C}$-points were determined according to the terms (4) and (5);

$$
\begin{aligned}
\rho= & 0^{\circ}, 90^{\circ} \Longleftrightarrow N_{0,90}(x)=N_{C}\left(M_{34,43}= \pm 1\right) \\
& +N_{L}\left(M_{24,42}=0\right), \\
\rho= & 45^{\circ}, 135^{\circ} \Longleftrightarrow N_{45,135}(x)=N_{L}\left(M_{34,43}=0\right) \\
& +N_{C}\left(M_{24,42}= \pm 1\right) ;
\end{aligned}
$$

(iv) statistical moments of the 1 st-4th orders of the obtained distributions of $N(x)$ amount of singularities were calculated according to the algorithms

$$
\begin{aligned}
& Z_{1}=\frac{1}{m \times n} \sum_{i=1}^{m \times n}|N(x)|, \\
& Z_{2}=\sqrt{\frac{1}{m \times n} \sum_{i=1}^{m \times n}[N(x)]^{2},} \\
& Z_{3}=\frac{1}{Z_{2}^{3}} \frac{1}{m \times n} \sum_{i=1}^{m \times n}[N(x)]^{3}, \\
& Z_{4}=\frac{1}{Z_{2}^{4}} \frac{1}{m \times n} \sum_{i=1}^{m \times n}[N(x)]^{4} .
\end{aligned}
$$

Figures 4, 5, and 6 show the networks of characteristic values $M_{44,24,34}^{*}(m \times n)$ of coordinate distributions of matrix elements $M_{44,24,34}(m \times n)$ of histological sections of skin derma of "A", "B", "C"-types.

Figure 7 illustrates the distributions of the number of characteristic values $N(x), N_{0,90}(x), N_{45,135}(x)$ of skin derma tissues of "A" (left column), "B" (central column), "C" (right column) types. 


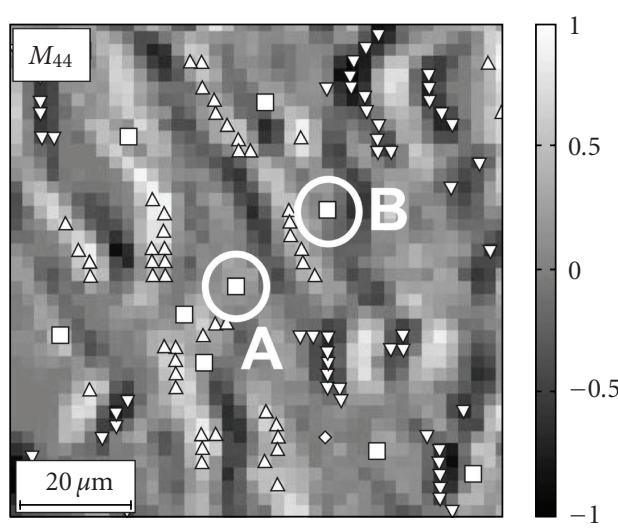

(a)

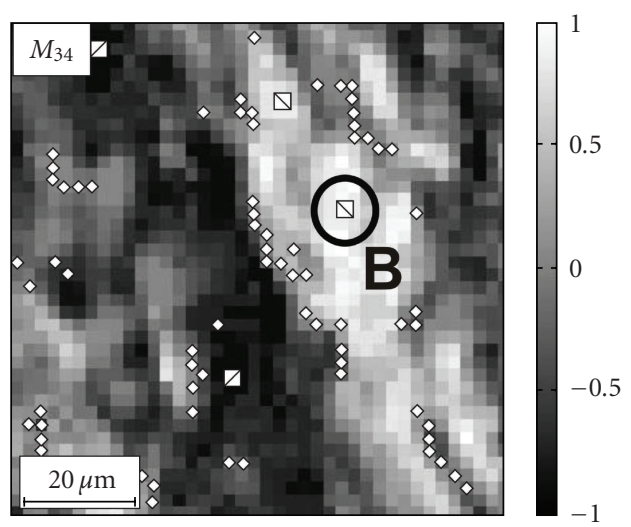

(c)

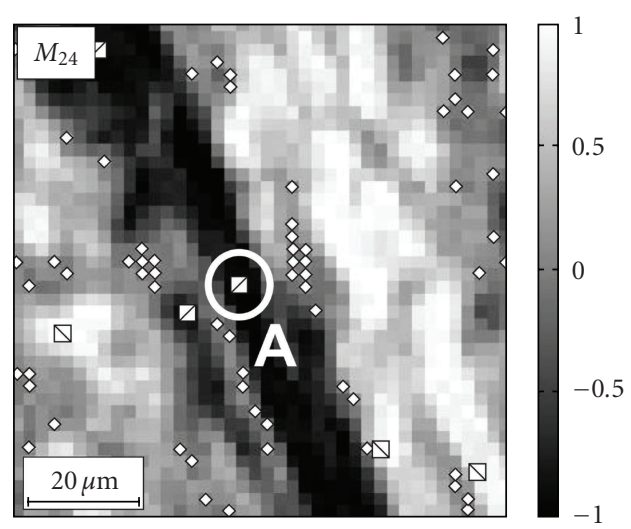

(b)

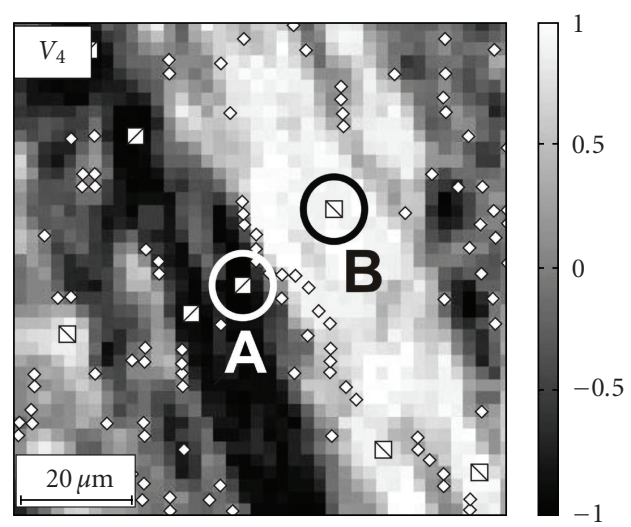

(d)

FIGURE 6: Networks of characteristic values $M_{44,24,34}^{*}(m \times n)$ of matrix elements $M_{44,24,34}(\mathrm{a}, \mathrm{b}, \mathrm{c})$ and singularities of polarization image of skin derma histological section of “C”-type $V_{4}(\mathrm{~d})$ : “ $\pm \mathrm{C}$ ”-points $(\square)\left(M_{44}=0\right)$; “+C"-points $(\nabla)\left(M_{24,34}=+1, V_{4}=+1\right)$; “-C”-points $(\square)$ $\left(M_{24,34}=-1, V_{4}=-1\right)$; “+L”- points $(\Delta)\left(M_{44}=+1\right)$; “-L”- points $(\nabla)\left(M_{44}=-1\right)$; “ \pm L”-points $(\diamond)\left(M_{24,34}=0, V_{4}=0\right)$.

The comparative analysis of the data obtained shows that

(i) coordinate distributions of the elements $M_{44,24,34}(m \times$ $n$ ) of Mueller matrix of skin derma tissue of all types is characterized by individual (according to quantitative and topological structure) networks of characteristic points (Figures 4-6);

(ii) total amount of \pm C-points $\left(M_{44}^{*}(m \times n)=0\right)$ sequentially increases for the samples of skin derma of "A", "B", "C" types (Figures 4(a)-6(a));

(iii) dependencies $N_{0,90}(x)$ of the number of characteristic values of matrix elements (8) and (9) for the samples of skin derma tissue of all types are similar in their structure (Figures 7(d), 7(e) and 7(f));

(iv) distributions $N_{45,135}(x)$ for the samples of skin derma tissue of " $B$ "-type are characterized by sufficient increase (by 2-3 times) of the number of characteristic values in comparison with similar dependencies $N_{0,90}(x)$ (Figures 7(e) and 7(h)).

The obtained results can be connected with the increase of birefringence $\left(\Delta n \approx 1.5 \times 10^{-2}\right)$ of collagen fibrils of pathologically changes skin derma of " $B$ "- and " $C$ "-types. Besides, at early stages (precancer) the directions of the growth of newly formed fibrils are being formed. At cancer states such pathologically changed fibrils form specifically oriented network of biological crystals.

In terms of physics, such morphological processes are manifested in the increase of probability of forming the $\pm \mathrm{C}$ points (skin derma samples of " $\mathrm{B}$ " and " $\mathrm{C}$ "-types), as well as in appearance of asymmetry between ranges of dependences values $N_{0,90}(x)$ and $N_{45,135}(x)$, which characterize the number of orthogonal L- and C-points.

In the end, the comparative investigations of diagnostic efficiency of the potential of famous techniques of laser polarimetry $\left(Z_{1,2,3,4}\left(M_{44,34,24}(m \times n)\right)\right)$ [27]; polarizationcorrelation mapping $\left(Z_{1,2,3,4}\left(V_{4}(m \times n)=\left\{\begin{array}{c}0, \\ \pm 1\end{array}\right)\right)[24,25]\right.$ and the technique of Mueller-matrix singular diagnostics $Z_{1,2,3,4}\left(N(x), N_{0,90}(x), N_{45,135}(x)\right)$ were suggested.

Table 1 presents statistical averaged values within the three groups of samples of myometrium tissue $\left(Z_{1,2,3,4}\left(M_{44,34,24}(m \times n)\right)\right) ;\left(Z_{1,2,3,4}\left(V_{4}(m \times n)=\left\{\begin{array}{c}0, \\ \pm 1\end{array}\right)\right)\right.$ and $Z_{1,2,3,4}\left(N(x), N_{0,90}(x), N_{45 ; 135}(x)\right)$.

It follows from the data presented that:

(i) efficiency of laser polarimetry for diagnostics and differentiation of early oncological changes of skin derma tissue is insufficient-the difference 


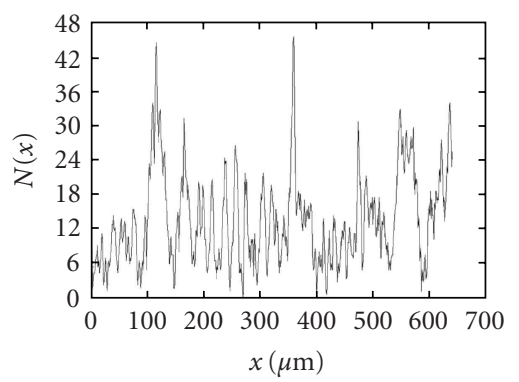

(a)

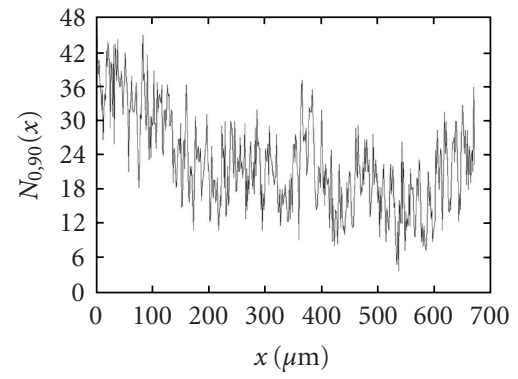

(d)

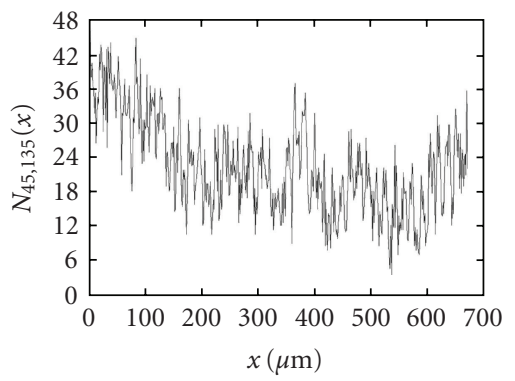

(g)

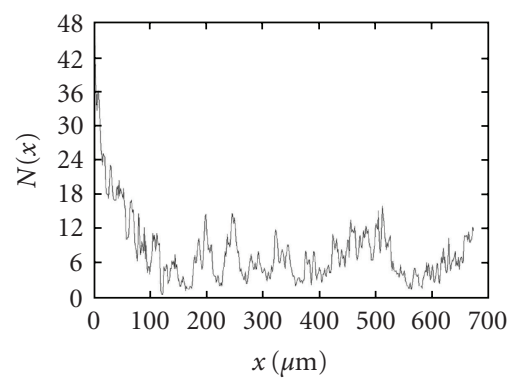

(b)

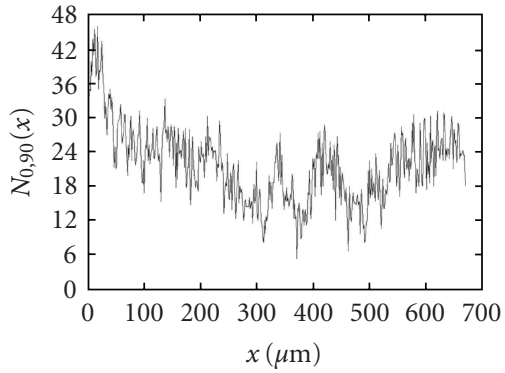

(e)

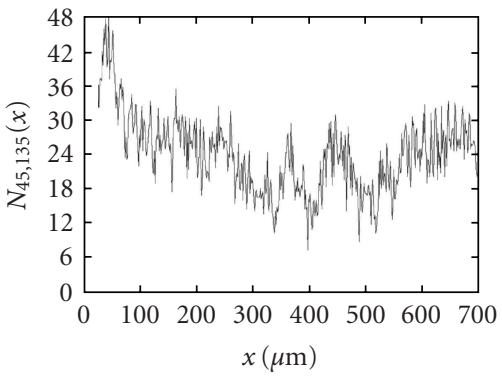

(h)

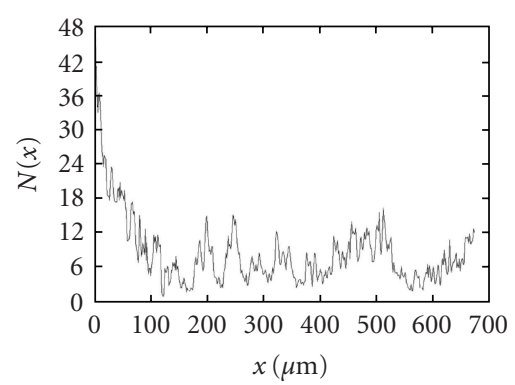

(c)

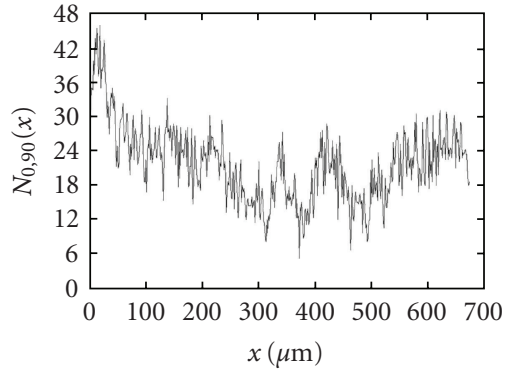

(f)

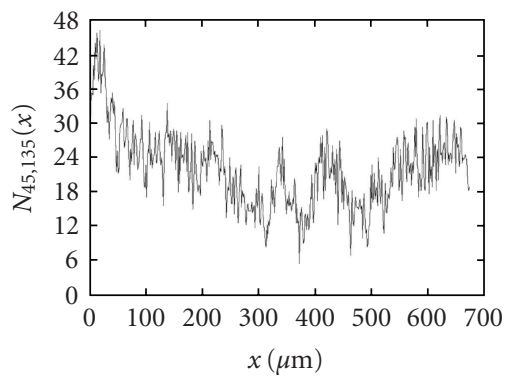

(i)

Figure 7: Distributions of the amount of characteristic values $N(x), N_{0,90}(x), N_{45,135}(x)$ of skin derma tissues of " $\mathrm{A}$ "-(left column), "B"(central column), "C" (right column)-types.

TABLE 1: Values $\left(Z_{1,2,3,4}\left(M_{44,34,24}(m \times n)\right)\right),\left(Z_{1,2,3,4}\left(V_{4}(m \times n)=0\right.\right.$, or \pm 1$\left.)\right)$ and $Z_{1,2,3,4}\left(N(x), N_{0,90}(x), N_{45 ; 135}(x)\right)$ statistically averaged within the three groups of skin derma samples.

\begin{tabular}{lccccccccc}
\hline \multirow{2}{*}{$Z_{j=1,2,3,4}$} & \multicolumn{2}{c}{ skin derma "A"-type (21 samples) } & \multicolumn{2}{c}{ skin derma “B”-type (21 samples) } & \multicolumn{2}{c}{ skin derma “C”-type (21 samples) } \\
& $M_{44}$ & $M_{34}$ & $M_{24}$ & $M_{44}$ & $M_{34}$ & $M_{24}$ & $M_{44}$ & $M_{34}$ \\
\hline$Z_{1}$ & $0,67 \pm 0.059$ & $0,32 \pm 0.031$ & $0,27 \pm 0.02$ & $0,59 \pm 0.048$ & $0,27 \pm 0.02$ & $0,24 \pm 0.05$ & $0,37 \pm 0.034$ & $0,19 \pm 0.015$ & $0,18 \pm 0.019$ \\
$Z_{2}$ & $0,51 \pm 0,046$ & $0,29 \pm 0,019$ & $0,26 \pm 0,021$ & $0,57 \pm 0,05$ & $0,23 \pm 0,013$ & $0,21 \pm 0,01$ & $0,28 \pm 0,023$ & $0,21 \pm 0,018$ & $0,17 \pm 0,015$ \\
$Z_{3}$ & $1,13 \pm 0,12$ & $0,88 \pm 0,09$ & $0,74 \pm 0,08$ & $0,98 \pm 0,1$ & $0,79 \pm 0,081$ & $0,66 \pm 0,069$ & $0,66 \pm 0,071$ & $0,49 \pm 0,042$ & $0,41 \pm 0,04$ \\
$Z_{4}$ & $3,15 \pm 0,32$ & $2,11 \pm 0,29$ & $2,27 \pm 0,31$ & $2,84 \pm 0,24$ & $1,79 \pm 0,18$ & $1,87 \pm 0,17$ & $1,57 \pm 0,14$ & $1,07 \pm 0,1$ & $1,12 \pm 0,11$ \\
\hline$Z_{j=1,2,3,4}$ & \multicolumn{2}{c}{$V_{4}=0$} & $V_{4}= \pm 1$ & \multicolumn{2}{c}{$V_{4}=0$} & $V_{4}= \pm 1$ & $V_{4}=0$ & $V_{4}= \pm 1$ \\
\hline$Z_{1}$ & $0.12 \pm 0,079$ & $0.24 \pm 0,038$ & $0.15 \pm 0,067$ & $0.28 \pm 0,068$ & $0.18 \pm 0,071$ & $0.29 \pm 0,076$ \\
$Z_{2}$ & $0.16 \pm 0,074$ & $0.31 \pm 0,042$ & $0.19 \pm 0,031$ & $0.38 \pm 0,052$ & $0.23 \pm 0,019$ & $0.4 \pm 0,048$ \\
$Z_{3}$ & $0.70 \pm 0,052$ & $0.92 \pm 0,086$ & $0.93 \pm 0,094$ & $1.12 \pm 0,101$ & $1.27 \pm 0,112$ & $1.72 \pm 0,123$ \\
$Z_{4}$ & $1.71 \pm 0,13$ & $2.19 \pm 0,18$ & $2.01 \pm 0,19$ & $3.13 \pm 0,27$ & $3.41 \pm 0,31$ & $4.01 \pm 0,31$ \\
\hline$Z_{j=1,2,3,4}$ & $N(x)$ & $N_{0,90}(x)$ & $N_{45,135}(x)$ & $N(x)$ & $N_{0,90}(x)$ & $N_{45,135}(x)$ & $N(x)$ & $N_{0,90}(x)$ & $N_{45,135}(x)$ \\
\hline$Z_{1}$ & $0,61 \pm 0,052$ & $0,43 \pm 0,038$ & $0,12 \pm 0,034$ & $0,39 \pm 0,05$ & $0,37 \pm 0,042$ & $0,23 \pm 0,048$ & $0,29 \pm 0,039$ & $0,28 \pm 0,036$ & $0,19 \pm 0,038$ \\
$Z_{2}$ & $0,75 \pm 0,068$ & $0,82 \pm 0,076$ & $0,15 \pm 0,021$ & $0,36 \pm 0,042$ & $0,69 \pm 0,056$ & $0,46 \pm 0,02$ & $0,31 \pm 0,024$ & $0,55 \pm 0,049$ & $0,23 \pm 0,026$ \\
$Z_{3}$ & $1,19 \pm 0,15$ & $0,92 \pm 0,01$ & $1,86 \pm 0,19$ & $0,63 \pm 0,051$ & $0,87 \pm 0,07$ & $1,86 \pm 0,19$ & $0,53 \pm 0,041$ & $0,76 \pm 0,062$ & $2,06 \pm 0,21$ \\
$Z_{4}$ & $1,99 \pm 0,17$ & $2,31 \pm 0,19$ & $2,32 \pm 0,21$ & $1,01 \pm 0,1$ & $2,07 \pm 0,17$ & $8,45 \pm 0,73$ & $0,8 \pm 0,07$ & $1,87 \pm 0,19$ & $2,91 \pm 0,32$ \\
\hline
\end{tabular}


between the values of statistical moments $\left(Z_{1,2,3,4}\left(M_{44,34,24}(m \times n)\right)\right)$ of samples "A", "B" and " $\mathrm{C}$ "-types is insufficient and does not exceed 20\%-45\%;

(ii) the technique of polarization-correlation mapping is efficient for differentiation of optical properties of sound and oncologically changed skin derma tissue-skewness $\left(Z_{3}\right)$ and kurtosis $\left(Z_{4}\right)$ of distribution of the number of singular points of " $\mathrm{A}$ "- and " $\mathrm{B}$ "types of laser images differ by 1.53 and 2.15 times;

(iii) the technique of Mueller-matrix singular diagnostics is efficient for differentiation of optical properties of all types of samples_-statistical moments of the 3rd and 4 th orders of distributions $N(x)$ for the samples "A", "B" and "C"-types differ by 1.7 and 2.5 times respectively;

(iv) for distributions $N_{45,135}(x)$ of the amount of orthogonal singular $\mathrm{L}_{45,135}$ - and $\mathrm{C}_{45,135}$-points of skin derma tissue of " $\mathrm{A}$ " and " $\mathrm{B}$ " types the maximal difference (from 2.2 to 4.1 times) is observed between all statistical $Z_{j=1,2,3,4}$.

\section{Conclusions}

Correlation between the coordinate locations of characteristic points of $2 \mathrm{D}$ elements of Mueller matrix of optically thin layer of biological tissue and the network of L- and C-points in its laser image is defined. The potentiality of Muellermatrix sampling of polarization singularities formed by biological crystals with orthogonally oriented $\left(\rho=0^{\circ}, 90^{\circ}\right.$ and $\rho=45^{\circ}, 135^{\circ}$ ) optical axes is shown. The efficiency of Mueller-matrix diagnostics not only for oncological changes of skin derma tissue but also for differentiating their severity degree is demonstrated.

\section{References}

[1] S. C. Cowin, "How is a tissue built?" Journal of Biomechanical Engineering, vol. 122, no. 6, pp. 553-569, 2000.

[2] O. V. Angelsky, A. G. Ushenko, Yu. A. Ushenko, Ye. G. Ushenko, Yu. Ya. Tomka, and V. P. Pishak, "Polarizationcorrelation mapping of biological tissue coherent images," Journal of Biomedical Optics, vol. 10, no. 6, Article ID 064025, 2005.

[3] J. F. de Boer and T. E. Milner, "Review of polarization sensitive optical coherence tomography and Stokes vector determination," Journal of Biomedical Optics, vol. 7, no. 3, pp. 359-371, 2002.

[4] J. F. de Boer, T. E. Milner, and J. S. Nelson, "Trends in optics and photonics (TOPS)," in Advances in Optical Imaging and Photon Migration, OSA, Washington, DC, USA, 1998.

[5] M. J. Everett, K. Schoenenberger, B. W. Colston Jr., and L. B. Da Silva, "Birefringence characterization of biological tissue by use of optical coherence tomography," Optics Letters, vol. 23, no. 3, pp. 228-230, 1998.

[6] O. V. Angelsky, Yu. Ya. Tomka, A. G. Ushenko, Ye. G. Ushenko, S. B. Yermolenko, and Yu. A. Ushenko, "2-D tomography of biotissues images in pre-clinic diagnostics of their pre-cancer states," in Advanced Topics in Optoelectronics, Microelectronics, and Nanotechnologies II, vol. 5972 of Proceedings of the SPIE, pp. 158-162, 2004.

[7] O. V. Angelsky, A. G. Ushenko, D. N. Burkovets, and Yu. A. Ushenko, "Polarization visualization and selection of biotissue image two-layer scattering medium," Journal of Biomedical Optics, vol. 10, no. 1, Article ID 014010, 2005.

[8] O. V. Angelsky, Yu. Ya. Tomka, A. G. Ushenko, Ye. G. Ushenko, and Yu. A. Ushenko, "Investigation of 2D Mueller matrix structure of biological tissues for pre-clinical diagnostics of their pathological states," Journal of Physics D, vol. 38, no. 23, pp. 4227-4235, 2005.

[9] S. Jiao, W. Yu, G. Stoica, and L. V. Wang, "Optical-fiber-based Mueller optical coherence tomography," Optics Letters, vol. 28, no. 14, pp. 1206-1208, 2003.

[10] Yu. A. Ushenko, "Statistical structure of polarizationinhomogeneous images of biotissues with different morphological structures," Ukrainian Journal of Physical Optics, vol. 6, pp. 63-70, 2005.

[11] O. V. Angel'skii, A. G. Ushenko, A. D. Arkhelyuk, S. B. Ermolenko, D. N. Burkovets, and Yu. A. Ushenko, "Laser polarimetry of pathological changes in biotissues," Optics and Spectroscopy, vol. 89, no. 6, pp. 973-978, 2000.

[12] O. V. Angelsky, A. G. Ushenko, and Yu. A. Ushenko, "Polarization reconstruction of orientation structure of biological tissues birefringent architectonic nets by using their Muellermatrix speckle-images," Journal of Holography and Speckle, vol. 2, pp. 72-79, 2005.

[13] J. F. Nye, Natural Focusing and the Fine Structure of Light, Institute of Physics, Bristol, UK, 1999.

[14] J. F. Nye, "Polarization effects in the diffraction of electromagnetic waves: the role of disclinations," Proceedings of the Royal Society of London A, vol. 387, no. 1792, pp. 105-132, 1983.

[15] O. V. Angelsky, A. P. Maksimyak, P. P. Maksimyak, and S. G. Hanson, "Interference diagnostics of white-light vortices," Optics Express, vol. 13, no. 20, pp. 8179-8183, 2005.

[16] J. F. Nye and J. V. Hajnal, "The wave structure of monochromatic electromagnetic radiation," Proceedings of the Royal Society of London A, vol. 409, no. 1836, pp. 21-36, 1987.

[17] M. V. Berry and M. R. Dennis, "Polarization singularities in isotropic random vector waves," Proceedings of the Royal Society A, vol. 457, no. 2005, pp. 141-155, 2001.

[18] A. D. Dolgov, A. G. Doroshkevich, D. I. Novikov, and I. D. Novikov, "Classification of singular points in the polarization field of the cosmic microwave background and eigenvectors of the Stokes matrix," JETP Letters, vol. 69, no. 6, pp. 427-433, 1999.

[19] A. I. Konukhov and L. A. Melnikov, "Optical vortices in a vector field: the general definition based on the analogy with topological solitons in a 2D ferromagnet, and examples from the polarization transverse patterns in a laser," Journal of Optics B, vol. 3, no. 2, pp. S139-S144, 2001.

[20] O. V. Angelsky, I. I. Mokhun, A. I. Mokhun, and M. S. Soskin, "Interferometric methods in diagnostics of polarization singularities," Physical Review E, vol. 65, no. 3, Article ID 036602, 5 pages, 2002.

[21] J. F. Nye, "Lines of circular polarization in electromagnetic wave fields," Proceedings of the Royal Society of London A, vol. 389, no. 1797, pp. 279-290, 1983.

[22] O. V. Angelsky, D. N. Burkovets, P. P. Maksimyak, and S. G. Hanson, "Applicability of the singular-optics concept for diagnostics of random and fractal rough surfaces," Applied Optics, vol. 42, no. 22, pp. 4529-4540, 2003.

[23] O. V. Angelsky, A. G. Ushenko, and Ye. G. Ushenko, "2-D Stokes polarimetry of biospeckle tissues images in pre-clinic 
diagnostics of their pre-cancer states," Journal of Holography and Speckle, vol. 2, pp. 26-33, 2005.

[24] O. V. Angelsky, A. G. Ushenko, Yu. A. Ushenko, and Ye. G. Ushenko, "Polarization singularities of the object field of skin surface," Journal of Physics D, vol. 39, no. 16, pp. 3547-3558, 2006.

[25] O. V. Angelsky, A. G. Ushenko, Ye. G. Ushenko, and Y. Y. Tomka, "Polarization singularities of biological tissues images," Journal of Biomedical Optics, vol. 11, no. 5, Article ID 054030, 2006.

[26] O. V. Angelsky, S. G. Hanson, A. P. Maksimyak, and P. P. Maksimyak, "On the feasibility for determining the amplitude zeroes in polychromatic fields," Optics Express, vol. 13, no. 12, pp. 4396-4405, 2005.

[27] A. G. Ushenko and V. P. Pishak, Coherent-Domain Optical Methods. Biomedical Diagnostics, Environmental and Material Science, Kluwer Academic Publishers, Dordrecht, The Netherlands, 2004. 

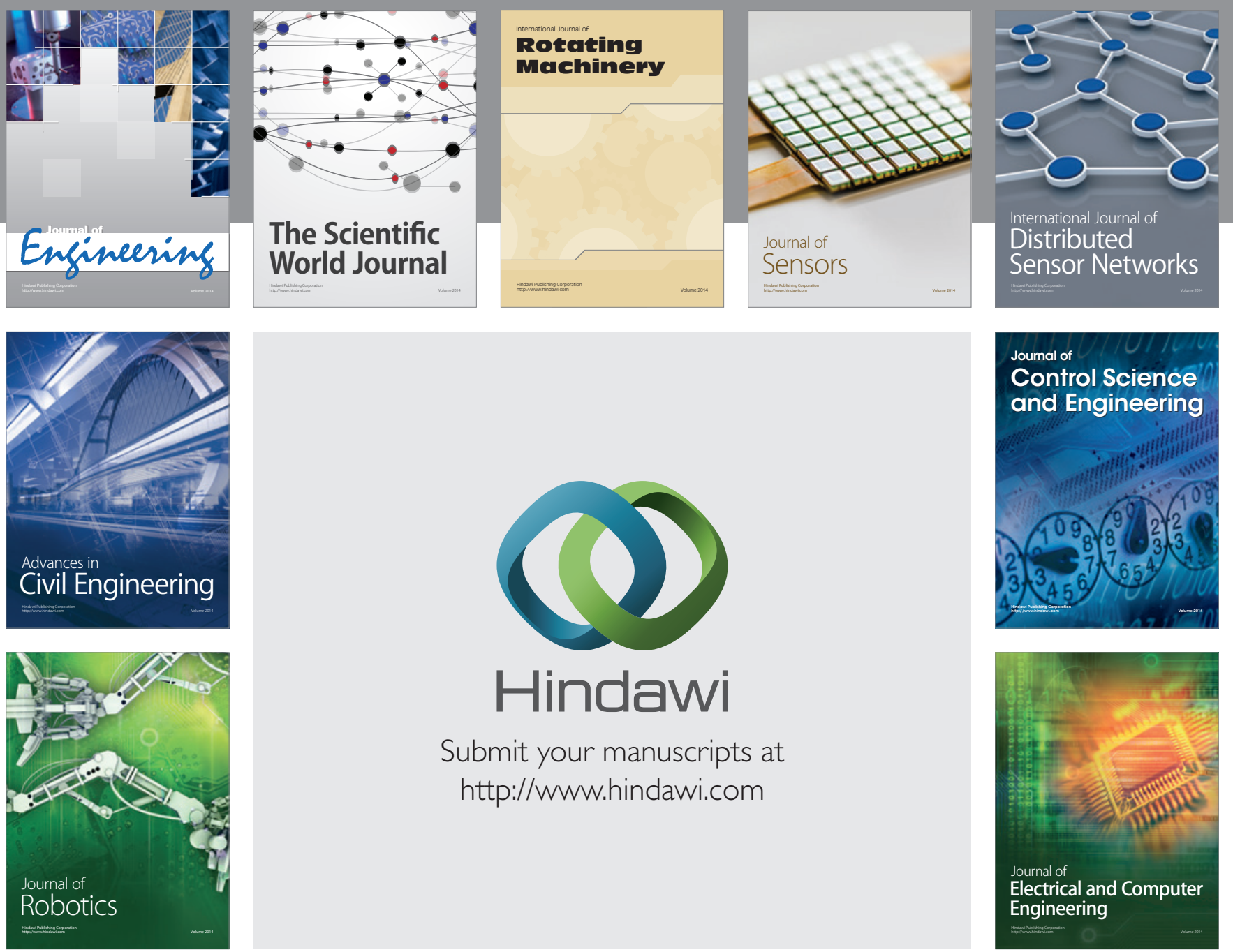

Submit your manuscripts at

http://www.hindawi.com
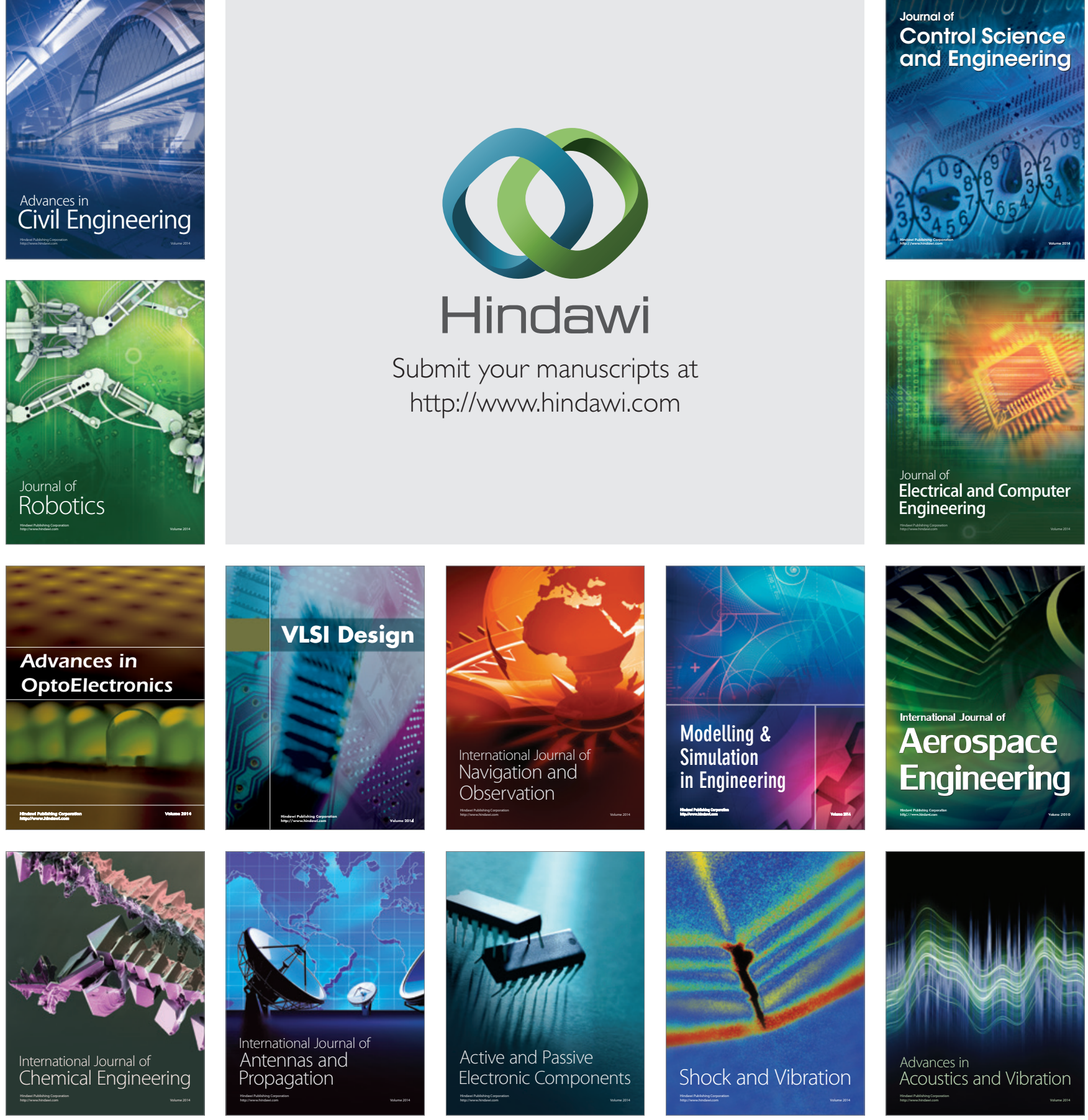